UNDERGRADUATE RESEARCH IN NATURAL AND CLINICAL SCIENCE AND TECHNOLOGY (URNCST) JOURNAL Read more URNCST Journal articles and submit your own today at: https://www.urncst.com

\title{
Research Fundamentals: The Research Question, Outcomes, and Background
}

Umair Majid, MSc [1] [2] [3]*

[1] Editorial and Advisory Board Member, URNCST Journal, Toronto, Ontario, Canada

[2] Curriculum Designer, Program Developer and Instructor, McMaster University, Hamilton, Ontario, Canada

[3] Director, The Methodologist (TMT), Mississauga, Ontario, Canada

*Corresponding Author: majidua@mcmaster.ca

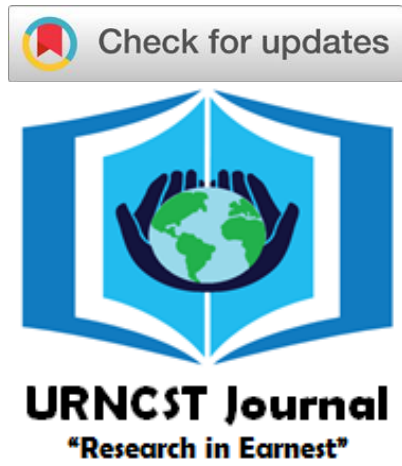

\begin{abstract}
This first article in a three-part series on research fundamentals describes the purpose and importance of writing a research protocol a priori to the research study and discusses three components of a research protocol for a clinical, quantitative research study. These components include the research question, outcomes and the background section including a literature review. By using the author's personal experience in writing and editing research protocols for international, peer-reviewed journals, and reviewing the literature on writing high quality research manuscripts, protocols and proposals, this three-part series provides a guideline for undergraduate researchers interested in publishing their research protocol in the Undergraduate Research in Natural and Clinical Sciences and Technology (URNCST) Journal.
\end{abstract}

Keywords: protocol; proposal; research question; research outcomes; literature review; undergraduate research; clinical research

\section{Introduction}

"For true success, ask yourself these four questions: Why? Why not? Why not me? Why not now?" - James Allen (British Author)

A research paper documents the study findings and its implications for the literature, practice, and policy. A research protocol, on the other hand, describes the intended outcomes, practices, and procedures of a research study. In other words, a research protocol contains the "ingredients" a researcher needs to conduct a research study.

The protocol is written a priori to the research study. The components of a protocol follow a logical flow similar to a clinical research manuscript. Writing a research protocol before conducting a study is essential because it enables the researcher to reflect on the study's objectives, receive feedback from colleagues, peers, supervisors and other stakeholders, and develop a plan that guides the researcher when conducting the research study [1]. Feedback allows the researcher to enhance the quality of the research, and in turn, increase the transferability and impact of the study findings.

Research protocols are especially important for studies that are longitudinal or situated across multiple sites, institutions, and countries. For these studies, the research protocol documents and standardizes the policies, practices, and procedures that all investigators and employees would follow at each research site. A research protocol also ensures that all researchers involved understand their roles, responsibilities, and collective objectives.

The components of a research protocol vary depending on the discipline and the objectives of the research study. In clinical research, a protocol usually comprises of an abstract, literature review, research question, research outcomes, study design and research approach, data extraction methods, data management policies, intended statistical procedures, the potential risk to subjects, threats to validity, works cited and appendices [2]. Viewing existing research protocols published in journals or on the websites of funding agencies provide excellent examples for researchers to frame their own research protocols (Cochrane Database, Journal of Medical Internet Research, and the BMC Series journals). Table 1 contains more information on the content of the components of a clinical research protocol.

Writing a research protocol may appear to be a significant challenge. However, in addition to the benefits it confers for conducting a research study, research protocols may be published in research journals depending on the discipline and topic. For example, the Cochrane Database accepts research protocols of randomized controlled trials (RCTs) for publication. The Cochrane community checks the information in these protocols to ensure that the intended procedures are rigorous and have high methodological quality. Moreover, the Undergraduate Research in Natural and Clinical Sciences and Technology (URNCST) Journal provides a platform to undergraduate researchers for publishing research protocols from their independent study 
UNDERGRADUATE RESEARCH IN NATURAL AND CLINICAL SCIENCE AND TECHNOLOGY (URNCST) JOURNAL Read more URNCST Journal articles and submit your own today at: https://www.urncst.com

Table 1: Topics Addressed in Each Research Protocol Component

\begin{tabular}{|c|c|}
\hline Protocol Component & Subsections \\
\hline Abstract & $\begin{array}{l}\text { An overview of the contents of a research protocol. This component tends to be op- } \\
\text { tional in clinical research protocols. }\end{array}$ \\
\hline Research Question & $\begin{array}{l}\text { The research question follows the PICO(TS) and FINER frameworks for effective } \\
\text { research questions. }\end{array}$ \\
\hline Research Outcomes & $\begin{array}{l}\text { A consideration of the primary and secondary objectives for conducting the research } \\
\text { study. }\end{array}$ \\
\hline Background & $\begin{array}{l}\text { An overview of the current research including the shortcomings, future directions, } \\
\text { and gaps to be addressed by the study. This section provides a convincing rationale } \\
\text { for conducting the study described in the research protocol. }\end{array}$ \\
\hline Study Design and Approach & $\begin{array}{l}\text { This section includes descriptions of the population(s) of interest, the eligibility cri- } \\
\text { teria, study setting(s), sampling strategy and calculations to computing the sample } \\
\text { size. }\end{array}$ \\
\hline Data Extraction Methods & $\begin{array}{l}\text { This section includes a statement on the ethics approval, description of the } 1^{\text {st }}, 2^{\text {nd }} \\
\text { and } 3^{\text {rd }} \text { contacts with the research participants, procedures for obtaining informed } \\
\text { consent, and the type, origin, and frequency of the data collected. }\end{array}$ \\
\hline Data Management Policies & $\begin{array}{l}\text { This section includes the policies governing data entry, data coding, and privacy and } \\
\text { confidentiality of data. }\end{array}$ \\
\hline Statistical Procedures & $\begin{array}{l}\text { This section describes the intended statistical procedures for obtaining descriptive } \\
\text { statistical data and the statistical analyses that address the research objectives of the } \\
\text { study. }\end{array}$ \\
\hline Risk to Subjects & $\begin{array}{l}\text { This section includes issues with informed consent, risks with the disclosure of sen- } \\
\text { sitive participant information, and issues that arise from the vulnerability of partici- } \\
\text { pants. Other ethical issues specific to the research design, approach and objectives } \\
\text { may also be discussed in this section. }\end{array}$ \\
\hline Threats to Validity & $\begin{array}{l}\text { This section discusses issues with confounding variables, sample size limitations, } \\
\text { and loss-to-follow-up. Other issues specific to the study may also be discussed in } \\
\text { this section. }\end{array}$ \\
\hline Works Cited/References & $\begin{array}{l}\text { The references usually follow the APA or MLA format according to the study disci- } \\
\text { pline and journal requirements. }\end{array}$ \\
\hline Appendices & $\begin{array}{l}\text { This section includes supplementary information relevant to conducting the research } \\
\text { study. Some examples include copies of survey measures to be used in the study, } \\
\text { interview guides, and additional sample size calculations. }\end{array}$ \\
\hline
\end{tabular}

projects [3]. In addition to a potential publication arising from the research study itself, undergraduate researchers can publish their research protocols in the URNCST Journal and further enhance their academic portfolio.

In this three-part series, the author discusses some considerations for writing a research protocol. These recommendations come from the author's own experience in not only writing research protocols but also editing them for international, peer-reviewed journals. This paper also derives reflections from the literature on how to write highquality research manuscripts, protocols, and funding proposals. Moreover, this series provides a guideline for undergraduate students interested in publishing their clinical research protocols in the URNCST journal. The suggestions provided are relevant to research protocols of quantitative, clinical research studies. Protocols of qualitative or mixedmethods research studies may be discussed in future editions.

In the first part of this series, the author discusses the following topics: (1) developing the clinical research ques- tion, (2) explicating the primary and secondary research outcomes, and (3) framing the background and literature review.

\section{Research Question}

Identifying Research Opportunities

The first step to writing a research question is to identify a research problem. Asking the right research question requires that the research problem (1) be compelling, and (2) important to the stakeholders [4]. In clinical research, there are multiple avenues to finding problems that could be explored through research inquiry [5] such as personal observations and experiences in the clinical environment, discussions with peers, colleagues, supervisors and patients, learnings and reflections from the literature, exploring medical technologies, and reflecting on changes to policy and practice $[6,7]$. A general approach to identifying clinical research problems is to have an open mind as you observe, read, and converse with others about clinical practice, poli$\mathrm{cy}$, and patient perspectives. 
UNDERGRADUATE RESEARCH IN NATURAL AND CLINICAL SCIENCE AND TECHNOLOGY (URNCST) JOURNAL Read more URNCST Journal articles and submit your own today at: https://www.urncst.com

\section{Writing Research Questions: PICO(TS)}

A clinical research question should follow the PI$\mathrm{CO}(\mathrm{TS})$ framework, which identifies the foundation of a research study. This framework is widely used in clinical research to explicate research questions. However, manuscripts seldom mention their research question in PICO(TS) format explicitly. The major benefit of using this frame- work comes from knowing that journal reviewers look for PICO(TS) when considering the clarity and impact of the research question [1]. Moreover, without a careful consideration of the research question, the study's methodological quality may be adversely influenced [5]. Table 2 provides more information on the PICO(TS) framework.

Table 2: The Components of a Research Question - PICO(TS)

\begin{tabular}{|l|l|}
\hline Population & $\begin{array}{l}\text { Identify the population of focus, the eligibility criteria for selecting a sample from the population, and } \\
\text { other features that define the population of interest. }\end{array}$ \\
\hline Intervention & $\begin{array}{l}\text { Identify the therapy, treatment, or approach that is reflective of the primary objectives of the research } \\
\text { study. }\end{array}$ \\
\hline Comparison & $\begin{array}{l}\text { Identify the therapy, treatment, or approach that the intervention will be compared within the research } \\
\text { study. }\end{array}$ \\
\hline Outcome & $\begin{array}{l}\text { Identify the measures (surveys, instruments, biological variables) that will be documented during the } \\
\text { study. }\end{array}$ \\
\hline Time & $\begin{array}{l}\text { Identify the duration of the study. This component is optional depending on the context and objectives } \\
\text { of the study. }\end{array}$ \\
\hline Setting & $\begin{array}{l}\text { Identify the study location. This component is optional because many studies can occur in multiple } \\
\text { institutions, nations, and jurisdictions. }\end{array}$ \\
\hline
\end{tabular}

Examples of Research Questions

For women between ages 20 and 45 at a women-only homeless shelter in Mississauga, ON, Canada, and who were victims of intimate partner violence in the past year, does Principle-Centred Therapy increases scores on the General Belongingness Scale over 8 weeks?

P: Women (ages 20-45) who were victims of intimate partner violence in the past year

I: Principle-Centred Therapy

C: Baseline (before) vs. Principle-Centred Therapy (after)

O: General Belongingness Scale

(T): 8 weeks

(S): A women-only homeless shelter in Mississauga, ON, Canada

For patients with low-risk prostate cancer, does external beam radiotherapy with a high dose-rate brachytherapy boost provide a superior relapse-free survival compared to external beam radiotherapy alone?

P: Patients with low-risk prostate cancer

I: External beam radiotherapy with high dose-rate brachytherapy boost

C: External beam radiotherapy alone

$\mathrm{O}$ : Relapse-free survival

(T): N/A

(S): N/A

Writing Research Questions: FINER

Writing effective research questions is essential for conducting a research study with high methodological quality and rigour. Effective research questions:

Majid | URNCST Journal (2017): Volume 1, Issue 2

DOI Link: https://doi.org/10.26685/urncst.14
(1) Improve the clarity of the problem being addressed

(2) Set the stage for an effective literature search

(3) Inform the efficient design and execution of the study

(4) Assess whether or not the study accomplished what it intended

The FINER acronym provides a guide for developing effective research questions. This framework provides five considerations when writing research questions. Table 3 describes each of these components in more detail.

In summary, developing a research question starts with problem identification then follows with the use of the PICO(TS) and FINER frameworks. Writing an effective research question starts with (1) identifying a research area worth exploring through research inquiry, (2) listing the elements of PICO(TS) for framing a research question, (3) specifying the elements of PICO(TS) as much as possible, (4) writing the research question in an interrogative format, (5) cross-checking whether or not all PICO(TS) elements are represented in the research question, and (6) crosschecking the research question with the FINER framework $[7,8]$.

\section{Research Outcomes}

Determining the objectives of a research study is a crucial aspect of planning for its successful implementation. The clinical research enterprise is guided by outcomes in health care, practice, and policy. Outcomes are variables that (1) indicate the impact or success of a project, and (2) can be measured objectively. This working definition of outcomes derives from not only health policy, clinical epidemiology, and healthcare research, but also entrepreneur- 
UNDERGRADUATE RESEARCH IN NATURAL AND CLINICAL SCIENCE AND TECHNOLOGY (URNCST) JOURNAL Read more URNCST Journal articles and submit your own today at: https://www.urncst.com

ship (key performance indicators) and project management (deliverables). In clinical research, the research objectives are referred to as clinical outcomes or endpoints.

\section{Types of Outcomes}

In clinical research studies, outcomes tend to be patient-relevant. The primary outcome is the foremost objective because it guides the understanding, design, and conduct of a research study. Research studies usually comprise of one primary outcome to ensure that the scope of the study is not too broad such that conducting the study becomes unfeasible, and not too specific that the findings cannot be transferred or generalized to other contexts. On the other hand, secondary outcomes are peripheral objectives that do not guide the design, implementation, and conduct of a research study but are nonetheless important to patients and/or the researchers.

Table 3: A Framework for Writing Effective Research Questions - FINER

\begin{tabular}{|l|l|l|}
\hline Feasible & - Will the study meet the sample size requirements? \\
& $-\quad$ Will the recruitment strategies reach the intended population? \\
& $-\quad$ Does the study have the relevant expertise? \\
& $-\quad$ Are the study objectives too broad (scope creep) for one study? \\
\hline Interesting & $-\quad$ Is the research question interesting to the researcher? \\
& $-\quad$ Is the research question aligned with the researcher's motivations? \\
\hline Novel & $-\quad$ Does the research question have a degree of novelty? \\
& $-\quad$ Does it advance the current literature? \\
& $-\quad$ Does it address some shortcomings of the literature? \\
\hline Ethical & $-\quad$ Does it explore an innovative topic? \\
\hline Relevant & $-\quad$ Can the research study obtain ethical approval? \\
& $-\quad$ Does the research study impose unnecessary harm to participants? \\
\hline
\end{tabular}

Two frameworks may assist researchers to formulate outcomes of a research study. The first framework describes some properties of good outcomes shown in Figure 1 [7]. The second framework is SMART, which outlines outcomes as specific, measurable, achievable, relevant, and timely [9]. These frameworks provide guidelines for formulating research outcomes that contain the information needed for project success.

\section{Examples of Outcomes}

This section uses examples of research questions to provide illustrate outcomes that are SMART and not SMART.

For patients with low-risk prostate cancer, does external beam radiotherapy with a high dose-rate brachytherapy boost provide a superior relapse-free survival compared to external beam radiotherapy alone?

Some SMART outcomes include:

- Relapse-Free Survival (RFS) - The time until the patient relapses as defined by an increase in the Prostate-Specific Antigen (PSA) $2 \mathrm{ng} / \mathrm{mL}$ above the lowest PSA value in the patient's history.

- Five-Year Survival - The percentage of patients who are disease-free five years subsequent to their prostate cancer diagnosis.

Majid | URNCST Journal (2017): Volume 1, Issue 2

DOI Link: https://doi.org/10.26685/urnest.14
Some outcomes that are not SMART include:

- Survival - This is not a SMART outcome because it is not sufficiently specific, and cannot be measured without a formal definition of survival. Five-year survival, relapse-free survival, and complication-free survival are examples of more specific outcomes.

- Health - This is not a SMART outcome because it is not sufficiently specific, and it cannot be measured adequately without a formal definition of health. Number of adverse events during surgery, and number of complications are examples of specific outcomes.

- Satisfaction - This is not a SMART outcome because it is not sufficiently specific. Satisfaction could relevant to life, surgery, family, work or other life domains. A specific outcome would measure satisfaction with life using Diener's Satisfaction with Life Scale (SWLS) [11]

- 10-Year Survival - This is not a SMART outcome if the resources available cannot sustain a 10-year study. In this case, the outcome is not timely and achievable.

- Adverse Events in Colorectal Cancer - This outcome may not be SMART because it is not relevant to patients who have prostate and not colorectal cancer. 
UNDERGRADUATE RESEARCH IN NATURAL AND CLINICAL SCIENCE AND TECHNOLOGY (URNCST) JOURNAL Read more URNCST Journal articles and submit your own today at: https://www.urncst.com

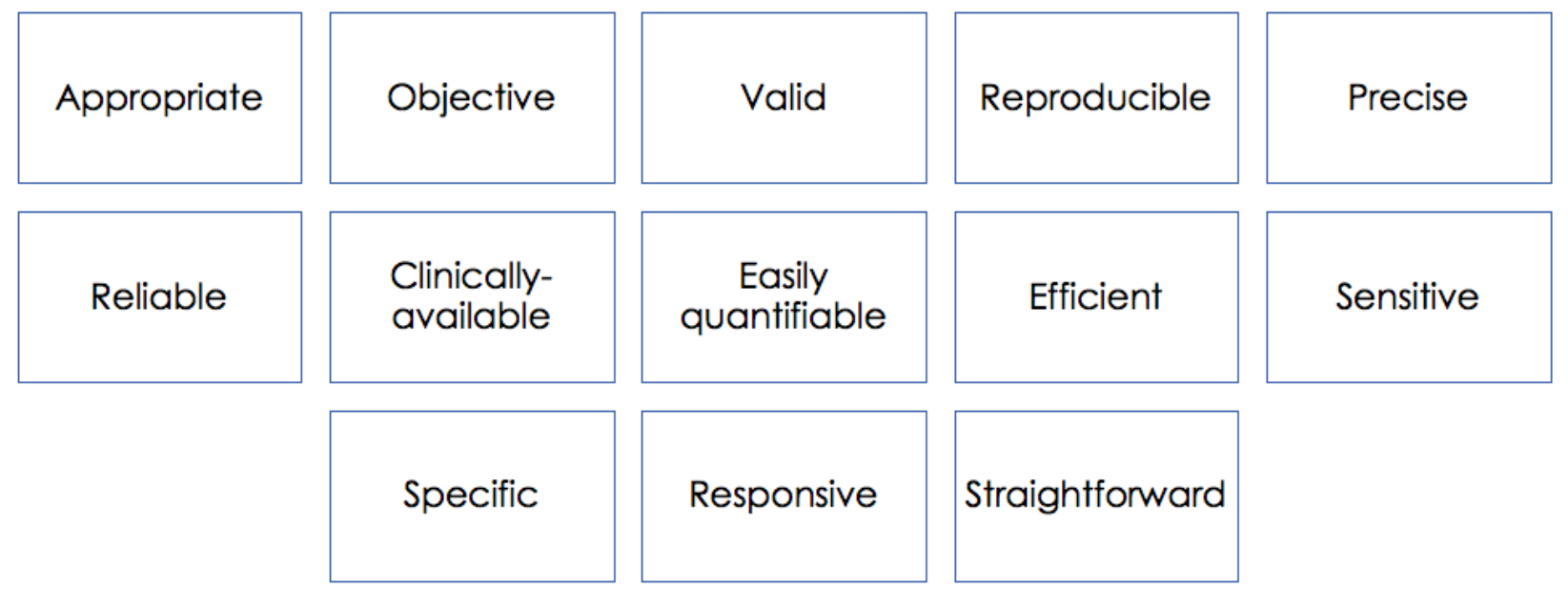

Figure 1: Some Properties of Good Outcomes in Clinical Research Studies [7]

\section{$\underline{\text { Scope of Outcomes }}$}

Sometimes, a researcher strives to accomplish numerous outcomes in one research study [5]. In such circumstances, the researcher should be cognizant of scope creep, which is attempting to achieve multiple primary and secondary outcomes in one research study. Scope creep is problematic because multiple outcomes will require more funding, expertise, and time. More outcomes in one research study mean that there will be more findings that need to be reported, which complicates the publication process when considering the strict word counts of journals. If there are too many research outcomes, then the study design may also become inefficient and lack the methodological rigour needed to answer the research question or achieve the outcomes [5]. There are five "filters" for assisting a researcher to prioritize research outcomes. These are the (1) relevance to patients, (2) relevance to learners, (3) feasibility given the resources, (4) level of patient and learner interest, and (5) frequency or urgency of the research problem [12].

One approach to ensuring that a research study has the appropriate scope is for the researcher to reflect on whether or not the outcomes can be split into two or more distinct research studies that would provide equally beneficial contributions to the literature. If this is the case, then the research study is treading towards scope creep. Another approach is to elicit feedback on the research objectives from peers, colleagues, supervisors, and managers. Sharing the research outcomes with others is a beneficial method to ensure that the outcomes of a research study are not beyond the scope of what the researcher can handle or accomplish given the resources [4]. In collaborative teams, however, the undergraduate researcher must respect the confidentiality and ownership of the work. Before submitting a research protocol to a journal for publication or presenting at conferences, the undergraduate researcher should consult with each team member. In the case that the team allows the undergraduate researcher to publish the research protocol, there should be a dialogue about the order of authorship (e.g., first, second third, and last authors).

\section{Conceptualization and Operationalization}

Sometimes, a researcher may identify a research problem but not in a form that allows for objective measurement. When this happens, the researcher should reframe the variables in the research problem to make them more appropriate for a research study [5]. There are two important definitions when thinking about outcomes and what they mean in the context of data collection, management, and analysis. Conceptualization refers to the process of identifying and clarifying abstract ideas into concepts that are understandable. For example, a feeling of fulfillment and satisfaction in life (abstract idea) may be identified by some as "meaning in life" (concept). Moreover, the feeling of mental and physical exhaustion observed in some clinicians (abstract idea) may be clarified to "compassion fatigue" (concept).

Operationalization, on the other hand, refers to the process of reframing a concept into a directly measured variable. For example, "meaning in life" (concept) may be measured by administering the Meaning in Life Questionnaire (MLQ) (measure) [13]. Moreover, "compassion fatigue" (concept) may be measured through the Professional Quality of Life Scale V (ProQOL) (measure) [14].

When thinking about the outcomes, the researcher should first conceptualize abstract ideas into discrete concepts and follow with operationalizing these concepts into directly measured variables. The researcher may use the existing literature to assist in conceptualization and operationalization by deriving from the seminal definitions of these concepts, administering surveys that are commonly utilized or have been validated from the literature, or reflect on the learnings from other scholars in the field.

\section{Background and Literature Review}

The literature review is a component of the background 
UNDERGRADUATE RESEARCH IN NATURAL AND CLINICAL SCIENCE AND TECHNOLOGY (URNCST) JOURNAL Read more URNCST Journal articles and submit your own today at: https://www.urncst.com

section of a research protocol. It provides an overview, integration, and synthesis of the findings from the literature relevant to the research question. This includes theoretical arguments concerning the relationships of relevant outcomes, findings from landmark studies on the topic, and shortcomings of the current literature. The literature review may be considered a representation of a systematic review, with the purpose of finding and describing all data pertinent to a research question. Without an adequate understanding of prior work on the topic, a researcher may not be able to justify their study design or approach convincingly [4].

This section of research protocols is a review of the current literature meaning that study findings should not be reported sequentially without making significant associations, links, and relationships between them. Instead, the literature review should provide an overview that integrates and synthesizes the findings from different studies presented in a story-like format that logically flows from one thought to the next.

The literature review also provides a convincing rationale for conducting a research study [1]. An important step to providing a convincing rationale is to link all findings discussed in the literature review to their real-world implications on knowledge, practice or policy. This requires the researcher to answer the "so what?" of both the current state of the literature and the research study being proposed. The researcher should also provide a clear description of how the research study contributes to the "so what?" and addresses some of the shortcomings of the literature [1].

Some questions to consider when writing the literature review:

- What is the problem that my literature reviewing is describing?

- What type of literature review am I conducting (methodology, policy, theory)?

- What is the scope of my literature review?

- Has my literature search been wide enough to ensure that I have found all relevant data?

- Has my literature search ensured that I have encountered sufficient relevant information?

- Have I critically appraised the quality, depth and breadth of the literature?

- Does the literature review provide a convincing rationale for conducting the study?

- Have I considered contrary perspectives to my current understanding of the literature?

- Who is the intended audience of the literature review?

- Will the readers understand the literature review?

- Will the readers find the literature review relevant, appropriate, and useful?

- Does the literature review addresses gaps in the literature?

\section{Conclusion}

This paper introduced the research protocol as a report that documents the outcomes, practices, and procedures of a research study. In this first article of a three-part series, the author discussed the importance of writing research protocols, provided frameworks for designing effective research questions and outcomes, and offered some considerations for writing a literature review. In the second article, the author will discuss the study design and approach, data extraction methods and data management procedures.

\section{Conflicts of Interest}

The author(s) declare that they have no conflicts of interest.

\section{Authors' Contributions}

UM: wrote the entire publication based on his experiences and knowledge in addition to the methodological literature on writing effective manuscripts, proposals and protocols.

\section{Acknowledgements}

Kevin Kim and Rita Morassut from the Department of Health Research Methods, Evidence and Impact (HEI) at McMaster University for their resources on writing research protocols.

\section{Funding}

This study was not funded.

\section{References}

[1] Hulley SB, Cummings SR, Browner WS, Grady DG, Newman TB. Designing clinical research. Lippincott Williams \& Wilkins; 2013 May 8.

[2] World Health Organization. Recommended format for a research protocol. Research Policy. 2017: http://www.who.int/rpc/research_ethics/format_rp/en/

[3] Ng JY. Introducing the undergraduate research in natural and clinical science and technology (URNCST) journal. URNCST Journal. 2017 Aug 08: 1(1): https://urncst.com/index.php/urncst/article/view/11/2

[4] Haynes, R. B., Sackett, D. L., Guyatt, G. H., \& Tugwell, P. (2006). How to do clinical practice research: a new book and a new series in the Journal of Clinical Epidemiology.

[5] Bragge P. Asking good clinical research questions and choosing the right study design. Injury. $2010 \mathrm{Jul}$ 31;41:S3-6. https://doi.org/10.1016/j.injury.2010.04.016

[6] Heddle NM. The research question. Transfusion. 2007 Jan 1;47(1):15-7. https://doi.org/10.1111/j.15372995.2007.01084.x

[7] Thabane L, Thomas T, Ye C, Paul J. Posing the research question: not so simple. Canadian Journal of Anesthesia/Journal Canadien D'Anesthésie. 2009 Jan 1;56(1):71. https://doi.org/10.1007/s12630-008-9007-4 
UNDERGRADUATE RESEARCH IN NATURAL AND CLINICAL SCIENCE AND TECHNOLOGY (URNCST) JOURNAL Read more URNCST Journal articles and submit your own today at: https://www.urncst.com

[8] Ranganathan P, Pantvaidya G, Pramesh CS, Badwe RA. Steps of a research study: From research question to publication. In: Cancer Research and Clinical Trials in Developing Countries 2016 (pp. 5-28). Springer International Publishing.

[9] Haughey D. SMART goals. Project Smart. 2013.

[10] Malone GP, Pillow DR, Osman A. The General Belongingness Scale (GBS): Assessing achieved belongingness. Personality and Individual Differences. 2012 Feb 29;52(3):311-6. https://doi.org/10.1016/j.paid.2011.10.027

[11] Diener ED, Emmons RA, Larsen RJ, Griffin S. The satisfaction with life scale. Journal of Personality Assessment. 1985 Feb 1;49(1):71-5. https://doi.org/10.1207/s15327752jpa4901_13
[12] Straus SE, Richardson W, Glasziou P, Haynes R. Evidence-based medicine: how to practice and teach EBM. Edinburgh: Elsevier; 16, 20, 21; 2005.

[13] Steger MF, Frazier P, Oishi S, Kaler M. The meaning in life questionnaire: Assessing the presence of and search for meaning in life. Journal of Counseling Psychology. 2006 Jan;53(1):80. https://doi.org/10.1037/0022-0167.53.1.80

[14] Black J, Cutler A, Pathy S, Sheth S. An assessment of professional quality of life and experience with critical incidents among OBGYN residents. Obstetrics \& Gynecology. 2016 Oct 1;128:43S. https://doi.org/10.1097/01.AOG.0000502674.89159.e7

\section{Article Information}

Managing Editor: Jeremy Y. Ng

Article Dates: Received Oct 19 17; Published Oct 2417

\section{Citation}

Please cite this article as follows:

Majid U. Research fundamentals: The research question, outcomes, and background. URNCST Journal. 2017 Oct 24: 1(2).

https://urncst.com/index.php/urncst/article/view/14

DOI Link: https://doi.org/10.26685/urncst.14

\section{Copyright}

(C) Umair Majid. (2017). Published first in the Undergraduate Research in Natural and Clinical Science and Technology (URNCST) Journal. This is an open access article distributed under the terms of the Creative Commons Attribution License (https://creativecommons.org/licenses/by/4.0/), which permits unrestricted use, distribution, and reproduction in any medium, provided the original work, first published in the Undergraduate Research in Natural and Clinical Science and Technology (URNCST) Journal, is properly cited. The complete bibliographic information, a link to the original publication on http://www.urncst.com, as well as this copyright and license information must be included.

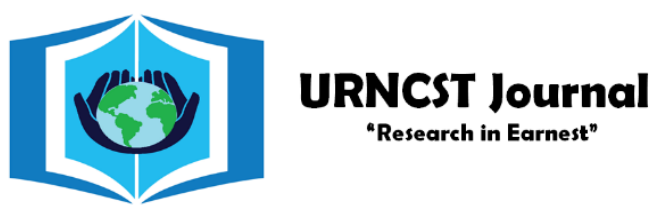

Do you research in earnest? Submit your next undergraduate research article to the URNCST Journal! | Open Access | Peer-Reviewed | Rapid Turnaround Time | International | | Broad and Multidisciplinary | Indexed | Innovative | Social Media Promoted | Pre-submission inquiries? Send us an email at info@urncst.com | Facebook, Twitter and LinkedIn: @URNCST Submit YOUR manuscript today at https://www.urncst.com! 